\title{
Die missverstandene Gewaltenteilung
}

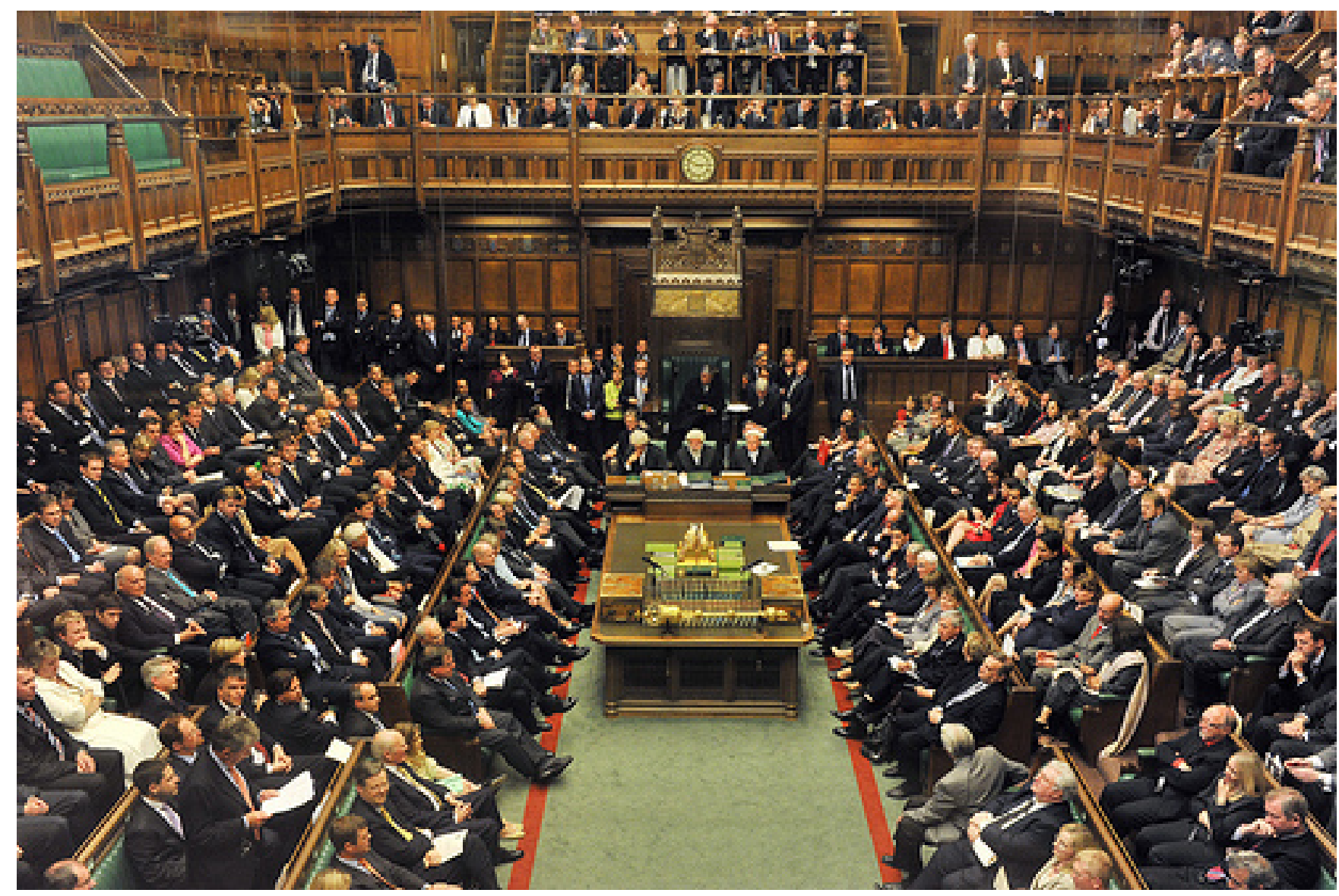

Das parlamentarische Regierungssystem wird oft missverstanden. So beklagte sich der - überaus kundige - ehemalige Bundesrichter und Bundestagsabgeordnete der Linken Wolfgang Neskovic in der Süddeutschen Zeitung über die enge Kooperation zwischen den Koalitionsfraktionen und der Bundesregierung. Er schlug ein Gesetz vor, dass eine solche Zusammenarbeit verbieten würde. Max Steinbeis schrieb in diesem Blog über die zunehmende Macht der Exekutive, die von keinem Parlament mehr kontrolliert würde. Beide Thesen sind sehr verbreitet, aber nicht wirklich richtig:

Im parlamentarischen Regierungssystem soll es keine Gewaltenteilung zwischen Regierungsfraktionen und Regierung geben. Darum wählt der Bundestag die Kanzlerin. Die Mehrheitsfraktionen arbeiten mit den politisch ernannten Teilen der Ministerialverwaltung zusammen, um Gesetze zu erarbeiten. Beide bilden, wie es der große Kenner des englischen Regierungssystems Walter Bagehot nannte, eine „Fusion“. Auch die Politisierung der Leitungspositionen in den Ministerien und deren Weisungsbefugnis ist kein Problem. Sie soll gerade dafür sorgen, dass die Vorbereitung der Gesetze ein demokratisches Mandat hat. Die eigentliche Linie der Gewalten-Teilung verläuft durch das Parlament, zwischen Regierung und Oppositionsfraktion. Aus diesem Grund ist es wichtig, dass die 
Opposition Informationsrechte gegenüber der Regierung hat. Sie muss die Kontrolle übernehmen und die wirklichen oder vermeintlichen Fehlleistungen einer Regierung im Parlament publizieren und politisieren. Die Mehrheit dagegen hat die Regierung zu stützen und ihre Politik öffentlich im Parlament vertreten.

Die Vorstellung, das Parlament müsse als Ganzes Gesetze schreiben und der Regierung als Organ kritisch gegenüberstehen, entstammt dem deutschen Kaiserreich. Hier war der Reichstag eine demokratisch legitimierte Daueropposition, der die Regierung aber nicht verantwortlich war. Die Regierung verfügte über eine vermeintlich „unpolitische“ Bürokratie, also eine demokratisch nicht verantwortliche, politisch konservative Beamtenkaste.

Ob Parlamente insgesamt an Macht verlieren, ist zumindest schwer zu sagen. Zum ersten wird diese Behauptung, die übrigens so alt ist wie der Parlamentarismus selbst, eigentlich immer ohne jeden historischen Vergleich erhoben. Nur: Wann war welches Parlament denn eigentlich mächtiger als heute? In Weimar? Im Frankreich der III. Republik? Zum zweiten ist unklar, wie man einen solchen Machtverlust in Systemen misst, in denen Regierung und Parlament ja gerade zusammengehören. Aus diesem Grund lassen sich parlamentarische Regierungen und das amerikanische Präsidialsystem, für das die meiste Literatur zu dem Thema existiert, nicht über einen Kamm scheren. Im amerikanischen System stehen sich Kongress und Präsident in der Tat als Konkurrenten gegenüber, weil beide direkt gewählt werden. Damit gelten andere Regeln. Zusätzlich kompliziert wird dies alles durch eine organisationstheoretische Einsicht: In einem gegebenen Regierungssystem gibt es keine konstante Menge an Macht. Wenn ein Organ mächtiger wird, muss deswegen nicht ein anderes an Macht verlieren. Vor vorschnellen Verfallsthesen sei also gewarnt.

(cc) $\mathrm{BY}-\mathrm{NC}-\mathrm{ND}$ 